DOI: $10.2478 / \mathrm{adms}-2019-0023$

\author{
A. Kausar* \\ Quaid-i-Azam University Campus, Nanosciences Division, National Center For Physics, \\ Islamabad, Pakistan \\ *asheesgreat@yahoo.com
}

\title{
ADVANCES IN CARBON FIBER REINFORCED POLYAMIDE-BASED COMPOSITE MATERIALS
}

\begin{abstract}
Carbon fiber has been used to reinforce both aliphatic and aromatic polyamides. Aliphatic polyamide is known as nylon and aromatic polyamide is often referred to as aramid. Among aliphatic polyamides, polyamide 6, polyamide 6,6, polyamide 11, polyamide 12, and polyamide 1010 have been used as matrices for carbon fiber. Factors affecting the properties of polyamide/carbon fiber composites are: fiber amount, fiber length, fiber orientation, matrix viscosity, matrix-fiber interactions, matrix-fiber adhesion, and conditions encountered during manufacturing processes. This article presents a state-of-the-art review on polyamide/carbon fiber composites. Polyamide/carbon fiber composites are lightweight and exhibit high strength, modulus, fatigue resistance, wear resistance, corrosion resistance, gear, electrical conductivity, thermal conductivity, chemical inertness, and thermal stability. Incorporation of oxidized or modified carbon fiber and nanoparticle modified carbon fiber into polyamide matrices have been found to further enhance their physical properties. Applications of polyamide/carbon fiber composites in aerospace, automobile, construction, and other industries have been stated in this review. To fully exploit potential of polyamide/carbon fiber composites, concentrated future attempts are needed in this field.
\end{abstract}

Keywords: Polyamide, carbon fiber, reinforcement, composite, strength

\section{INTRODUCTION}

Thermoplastic polyamides have low density, fine strength, and heat stability, due to which they are extensively employed in aircraft, aerospace, automotive and other industries [1-3]. In this regard, aliphatic (nylons) and aromatic (aramids) polyamides have been applied in high performance industrial materials [4-6]. Pristine carbon fiber (CF) possesses fine mechanical, thermal and electrical properties [7]. CF has been used as effectual nanofiller for thermoplastic polymers especially polyamide matrices. Carbon fiber filled nylon and aramid composites have concerned considerable research consideration [8]. The physical properties of polyamide/carbon fiber composites can be varied by altering the parameter of fiber content, fiber length, fiber orientation, and polyamide-fiber linkage. Various processing techniques have been used for fabricating the polyamide/carbon fiber composites such as solution method, resin infiltration, 
polymer impregnation, melt mixing, extrusion, injection molding, electrospinning, and spin coating methods [9]. Mechanical properties, thermal stability, conductivity, and anticorrosion properties of carbon fiber reinforced polymer composites have been significantly considered. Applications of polyamide/carbon fiber composites are wide ranging from aerospace/automobile - to - construction - to - textile/electronics industries [10]. Specifically, the polyamide/CF composites have been used to form lightweight automotive parts and aerospace structural applications [11-13]. An important application of carbon fiber/p-aramid composites has been found for industrial helmets [14]. Polyamide/CF composites have also been applied for the structural reinforcement of masonry building [15]. Carbon fiber reinforced polyamide composites possess extremely high strength to be utilized in civil and structural engineering [16, 17]. In all these applications, high strength, thermal stability, and heat conduction of the polyamide/CF composites are desirable $[18,19]$. In this regard, the $\mathrm{CF}$ cutting performance, machining, machining mechanism, and processing approaches must be optimized to enhance the characteristics and applications of the polyamide/carbon fiber composites [20].

In a nutshell, this review provides a comprehensive overlook on polyamide, carbon fiber, and their derived composites. Indispensable facets, physical properties, and processing strategies of polyamide/carbon fiber composites have been systematically reviewed. Progress in the polyamide/carbon fiber composites has revealed significant applications in space, aircraft, automobile, and other technical industries.

\section{POLYAMIDE MATRIX}

Polyamide (PA) is an engineering thermoplastic material. Polyamides have been frequently used in fibers, films, and sheets owing to fine mechanical and thermal properties [21]. Polyamides exits in both the aliphatic and aromatic forms [22]. Aliphatic polyamide is usually known as nylon and aromatic polyamide is referred as aramid. The crystal structure in polyamides consists of ( $i$ ) $\alpha$ crystalline phase; (ii) $\beta$ crystalline phase; and (iii) $\gamma$ crystalline phase. There is wide range of aliphatic polyamides available including polyamide 6 , polyamide 6,6 , polyamide 11 , polyamide 12 , polyamide 1010 , etc. Aromatic polyamides have also gained significance. Polyamides have good transparency, high strength, modulus, rigidity, hardness, chemical resistance, thermal resistance, and moisture absorption properties [23]. The physical properties of polyamides have been improved by inclusion of organic and inorganic nano-filler [24]. Hydrogen bonding interactions exist in polyamide backbone between amide linkage and oxygen of carbonyl groups $[25,26]$. Polyamides have several technical applications in automotive, aerospace, construction, textile, electronics, etc. [27-30].

\section{CARBON FIBER REINFORCEMENT}

Carbon fiber $(\mathrm{CF})$ has been used as an efficient reinforcement for polymers [31]. However, carbon fiber has also been reinforced in cementitious and carbon-carbon composite. Polymer/carbon fiber composites possess light weight, high specific strength, specific modulus, fatigue resistance, and corrosion resistance [32, 33]. Carbon fiber reinforced plastic is often known as CFRP. Various routes have been used to modify pristine carbon fiber. Fig. 1 shows 
scanning electron microscopy (SEM) images of neat and modified carbon fiber. Neat carbon fiber owns fine electrical conductivity, thermal conductivity, and low thermal expansion coefficient $[34,35]$.
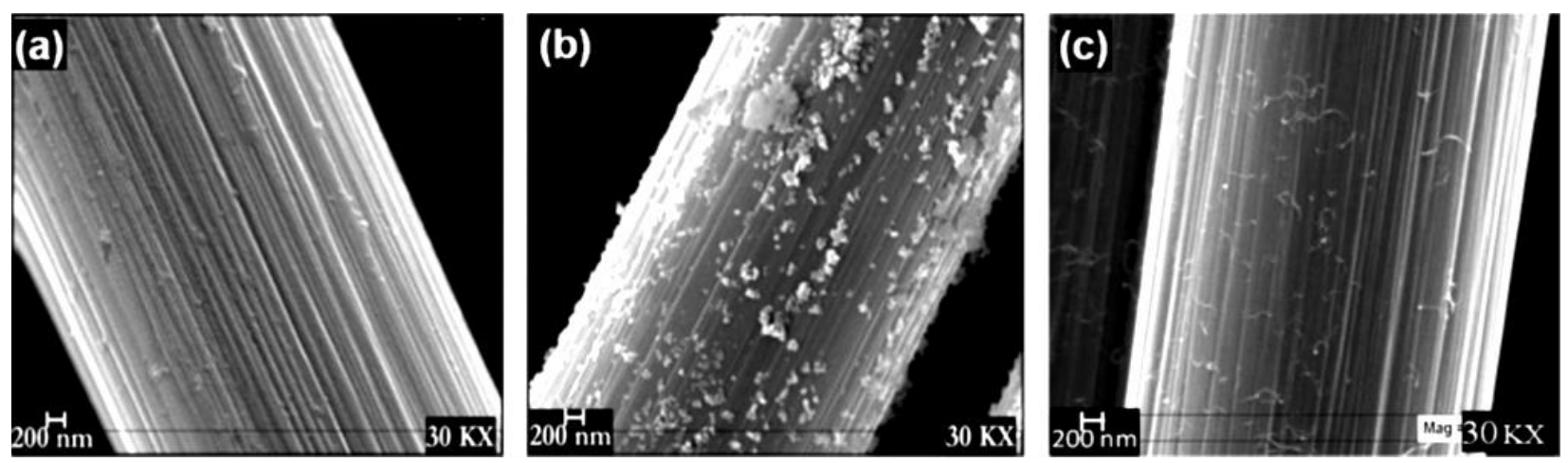

Fig. 1. SEM micrographs of carbon fiber: (a) without sizing; (b) sized with nano rare earth particle modification; and (c) sized with MWCNT [40]

Neat carbon fiber also possesses outstanding strength, stiffness, chemical inertness, and thermal stability. Carbon fiber modified with metal nanoparticle and nanocarbon have further enhanced the structural and physical properties. Consequently, carbon fiber has been used in high temperature demanding strengthening applications [36]. Metal-based composites have been frequently replaced with CFRP in aerospace and automobile industries. Proprieties of CRRP have been upgraded considering the factors such as fiber dispersal, fiber volume fraction, compatibility between resin-fiber, interfacial contact, and resin impregnation. Interfacial strength of CFRP can be improved via selecting suitable surface treatment to enhance the matrix-filler adhesion [3740].

\section{CARBON FIBER REINFORCED POLYAMIDE COMPOSITE}

\section{Polyamide 6/carbon fiber}

Polyamide 6 (PA6) and carbon fiber composites have been prepared through injection molding, solution mixing, and resin infiltration techniques [41]. The properties of short fiber $\mathrm{CF}$ and long fiber CF filled PA6 have been investigated $[42,43]$. The fiber length and amount may play an important role in increasing the composite efficiency, along with resin viscosity. Luo et. al. [44] designed polyamide 6 and long carbon fiber reinforced (PA6/LCF) composites using melt impregnation. The influence of fiber sizing on dispersion, resin flowability, and mechanical properties of the PA6/LCF composite was studied. Fig. 2 shows the sizing treatment process using homemade setup. The sizing solution in ultrasonic bath was used to size the carbon fiber tow. The rapid tow wetting was carried out through capillary forces and resin rising in $\mathrm{CF}$ network. Fig. 3 illustrates the tensile load-displacement curves of LCF/PA6 composites. The varying sizing concentrations of $20 \mathrm{wt} . \% \mathrm{CF}$ were used. The $22 \mathrm{wt} . \%$ sizing concentration led to enhanced load and displacement properties [45]. At this sizing concentration, the composite revealed highest energy absorption. According to morphology analysis in Fig. 4, the reinforcing 
effect of carbon fiber $>20 \mathrm{wt}$. \% was due to the filler aggregation. The discontinuous carbon fiber may lead to reduced impact strength of these composites.

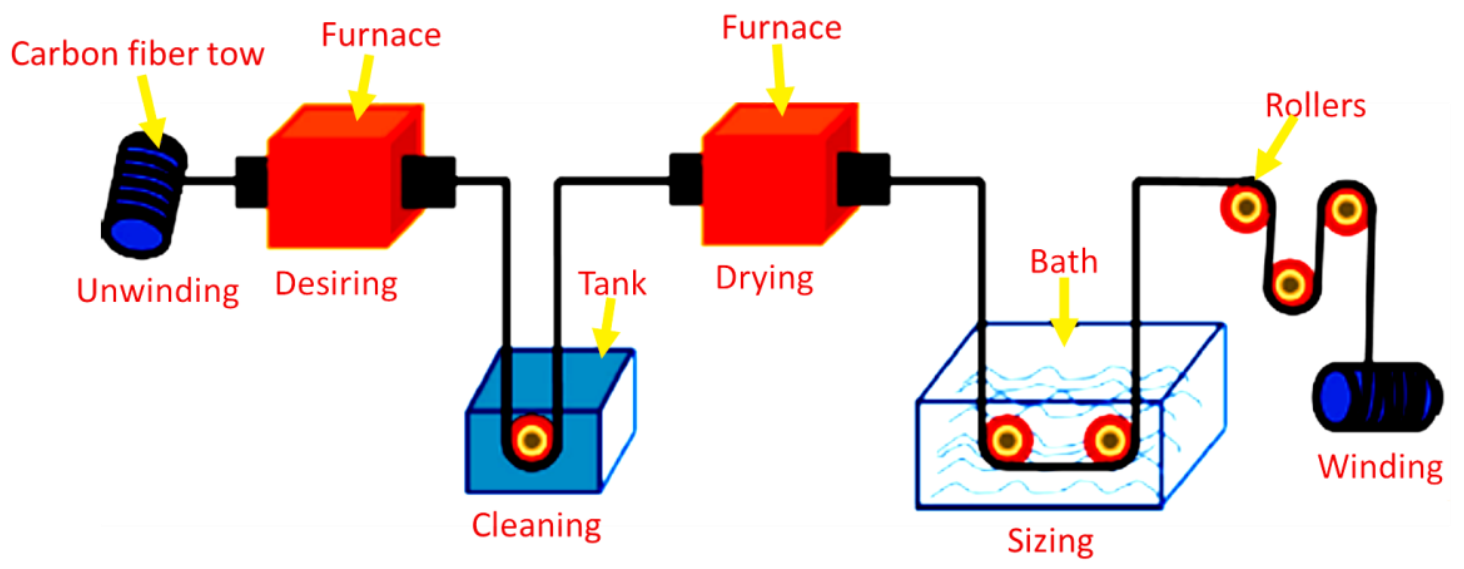

Fig. 2. Schematic diagram of the process for sizing treatment of continuous carbon fibers [43]

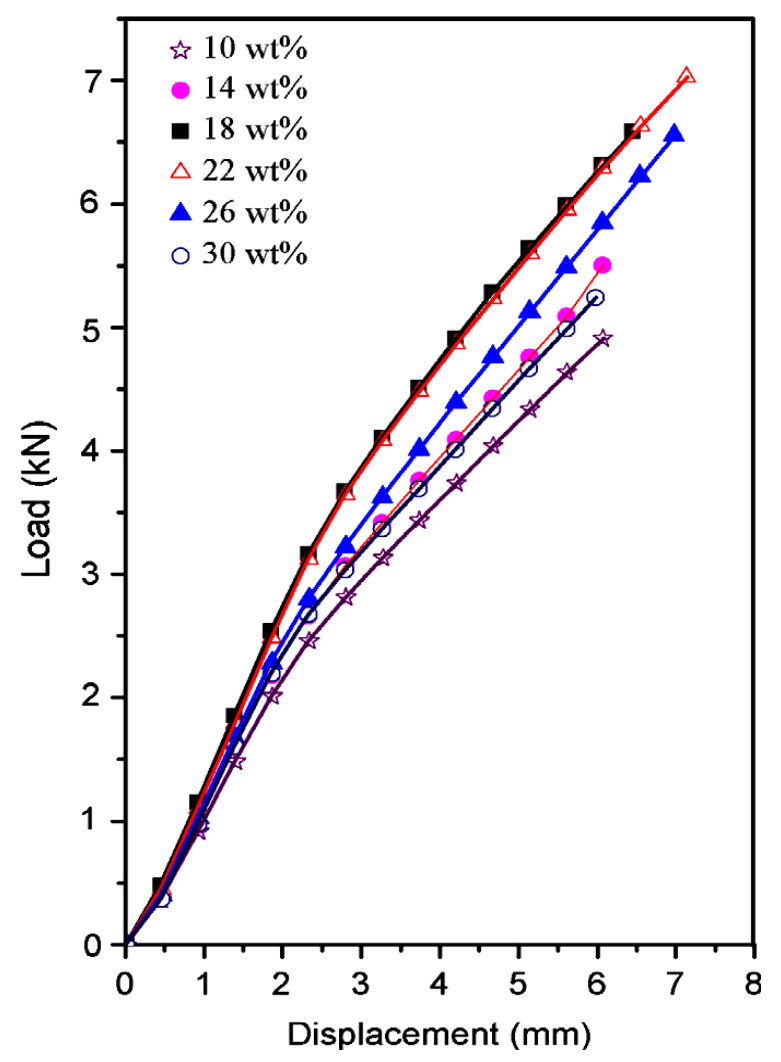

Fig. 3. Typical tensile load-displacement curves of PA6/LCF composites reinforce with $20 \mathrm{wt} . \%$ carbon fibers sized at varying sizing concentration [43] 

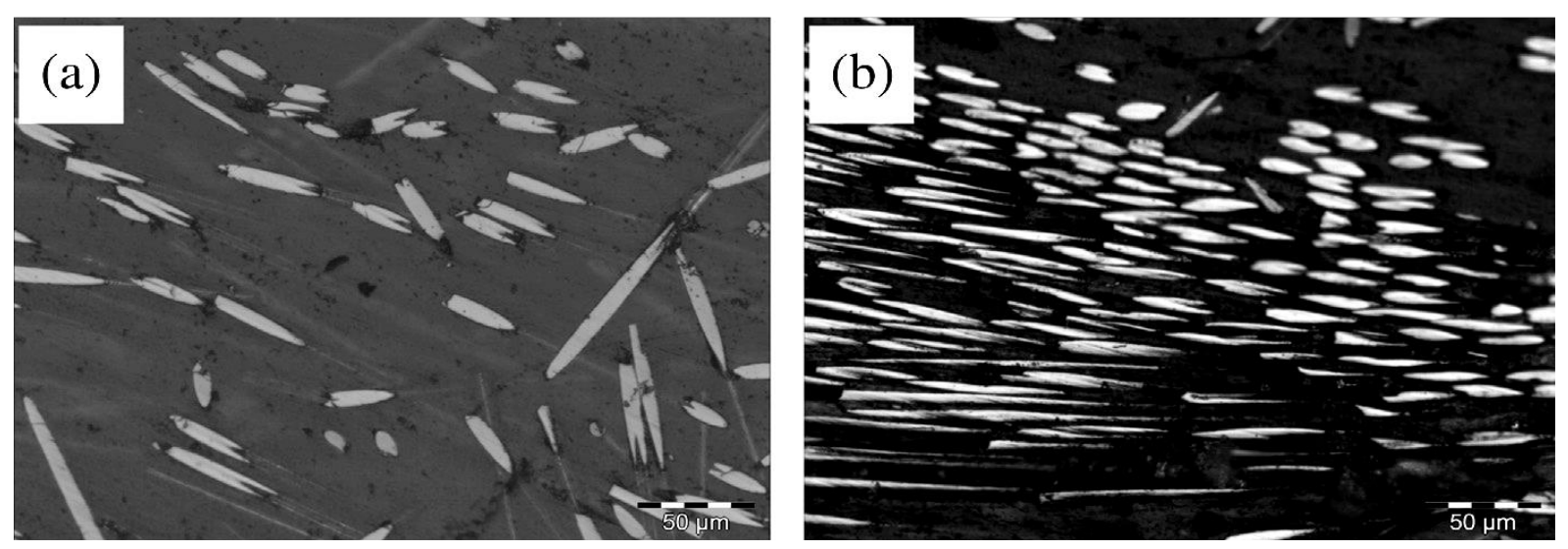

Fig. 4. Microstructure of PA6/LCF composites showing (a) uniform fiber distribution in the composite with 20 wt.\% carbon fibers and (b) typical fiber aggregation in the composite with 24 wt.\% carbon fibers [43]

$\mathrm{Wu}$ et. al. [46] prepared carbon fiber reinforced polyamide 6 composite. The mechanical properties of $10 \mathrm{wt} . \%$ carbon fiber reinforced composite were considerably higher than the neat polyamide 6 . The tensile strength and modulus of polyamide $6 / \mathrm{CF}$ were found higher $(70.9 \mathrm{MPa}$ and $3261 \mathrm{MPa}$, respectively), compared with the neat polyamide 6 (strength $=51.8 \mathrm{MPa}$ and modulus $=1073 \mathrm{MPa}$ ).

$\mathrm{Li}$ et. al. [47] formed modified carbon fiber through $\mathrm{O}_{3}$ modification of polyacrylonitrile. The flexural strength of $\mathrm{O}_{3}$ treated carbon fiber-based composite was augmented by $60 \%$, relative to neat polyamide. Karsli et. al. [48] reinforced polyamide 6 with CF through melt mixing technique. Fig. 5 shows the effect of fiber content and length on the hardness PA6/CF composite. The hardness values of composite were increased with the CF content. Instead, hardness values of composites were not affected by the fiber length. Scanning electron microscopy (SEM) images of short carbon fiber filled PA6 composites are shown in Fig. 6. Different shares of $1.2 \mathrm{~cm}$ long $\mathrm{CF}$ were used in the polyamide matrix.
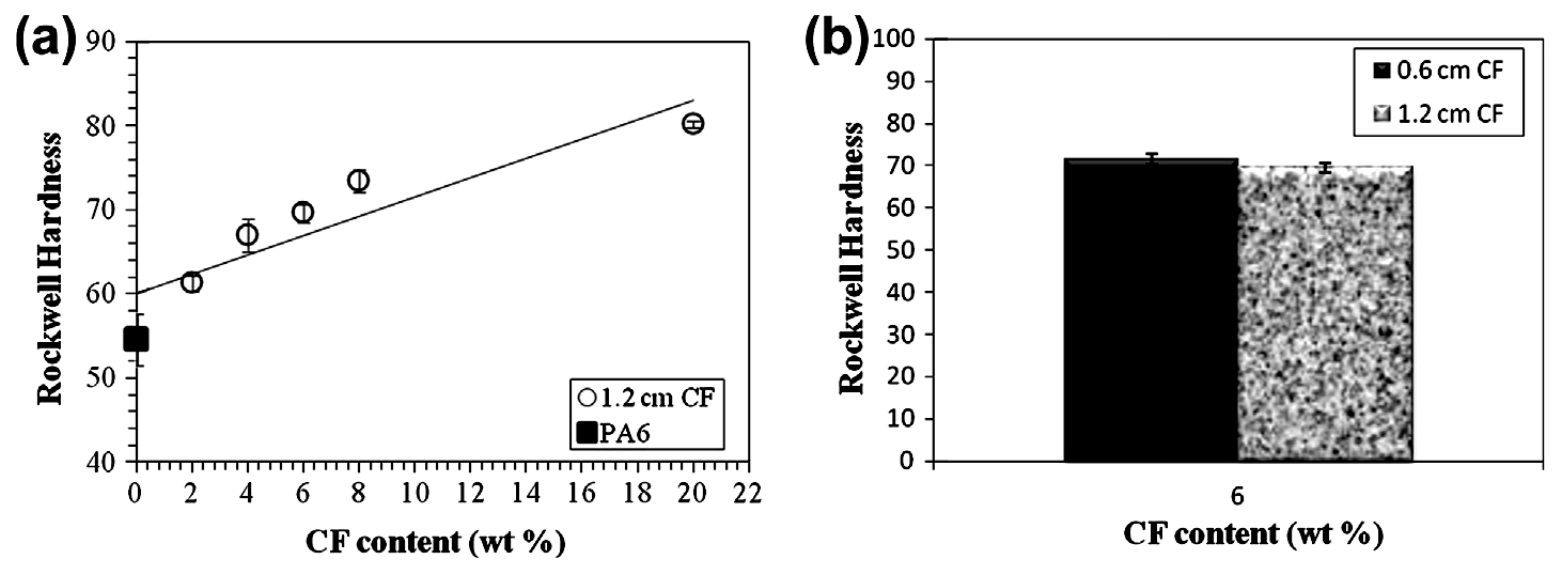

Fig. 5. Effect of fiber content and length on the Rockwell hardness values of PA6/CF composites, (a) effect of fiber content and (b) effect of fiber length [48] 

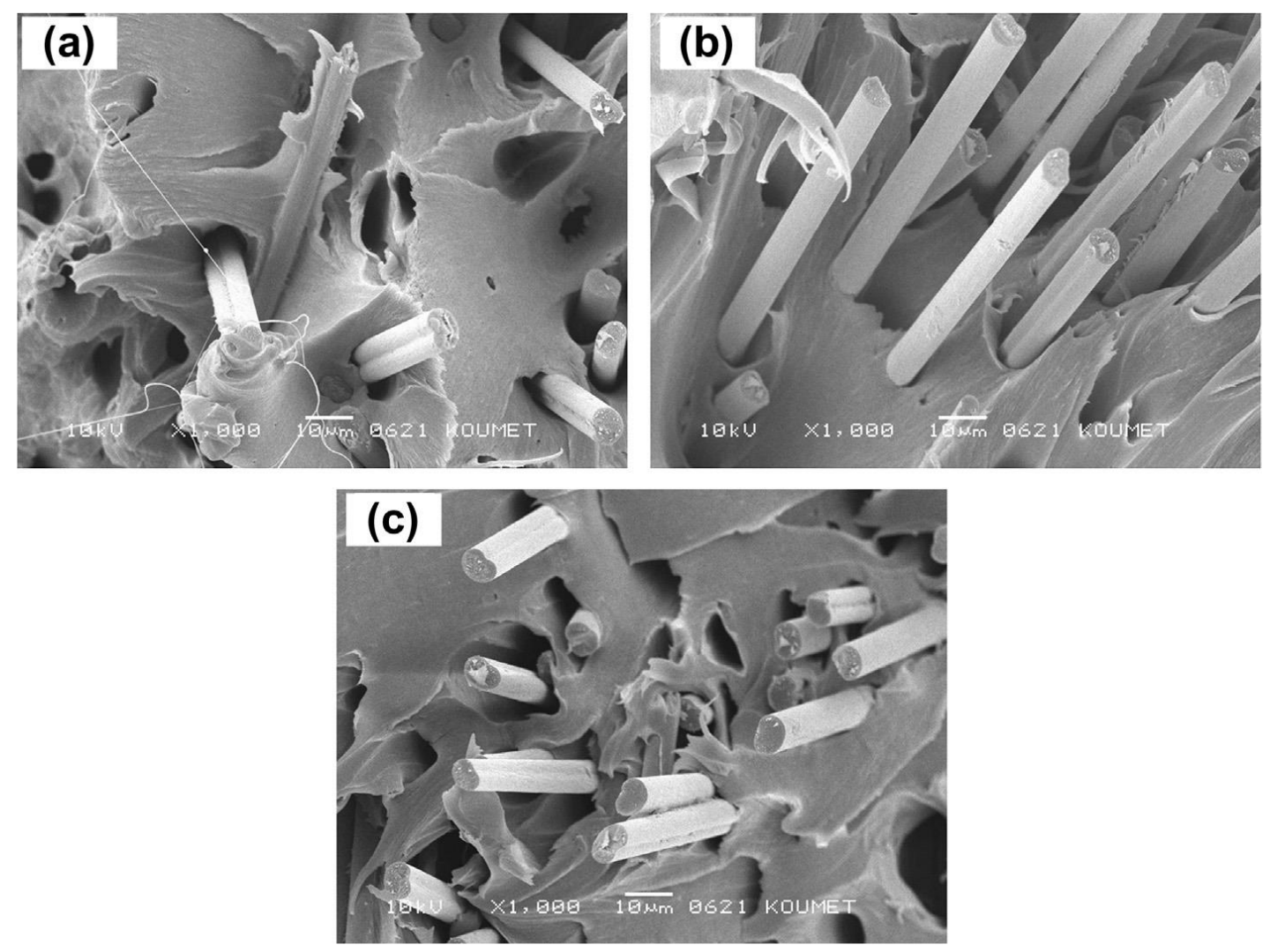

Fig. 6. SEM micrographs of tensile fracture surfaces of PA6/CF composites, (a) $1.2 \mathrm{~cm}-4 \%(\times 1000)$, (b) $1.2 \mathrm{~cm}-6 \%(\times 1000)$, and (c) $1.2 \mathrm{~cm}-8 \%(\times 1000)[48]$

The pulled out fibers were observed in the micrographs of the fractured composites [49]. The CF were also not coated with polyamide matrix owing to weak interfacial adhesion between matrix-fiber. Ma et. al. [50] produced unidirectional carbon fiber reinforced PA6 composite. Table 1 shows mechanical properties of PA6, CF, and PA6/CF composite. The strength and modulus properties of PA6/CF composite were found to improve, compared with the neat PA6 matrix. The development in the mechanical properties can be well understood through the morphological analyses. Fig. 7 shows that the crack was propagated into fiber rich areas with the increase in tensile strain. The fiber breakage was also found to improve with strain enhancement. In polyamide 6/carbon fiber composite, mostly studied properties are morphology, strength, modulus, toughness, hardness, and crack propagation. Modification of carbon fiber has also been used to develop the properties and performance of PA6/CF composites.

Table 1. Mechanical properties of materials [50]

\begin{tabular}{lcc}
\hline \multicolumn{1}{c}{ Material } & Modulus, GPa & Strength, MPa \\
\hline CF & 230 & 4000 \\
PA6 & 2.4 & 82 \\
PA6/CF & 8.2 & 1308 \\
\hline
\end{tabular}



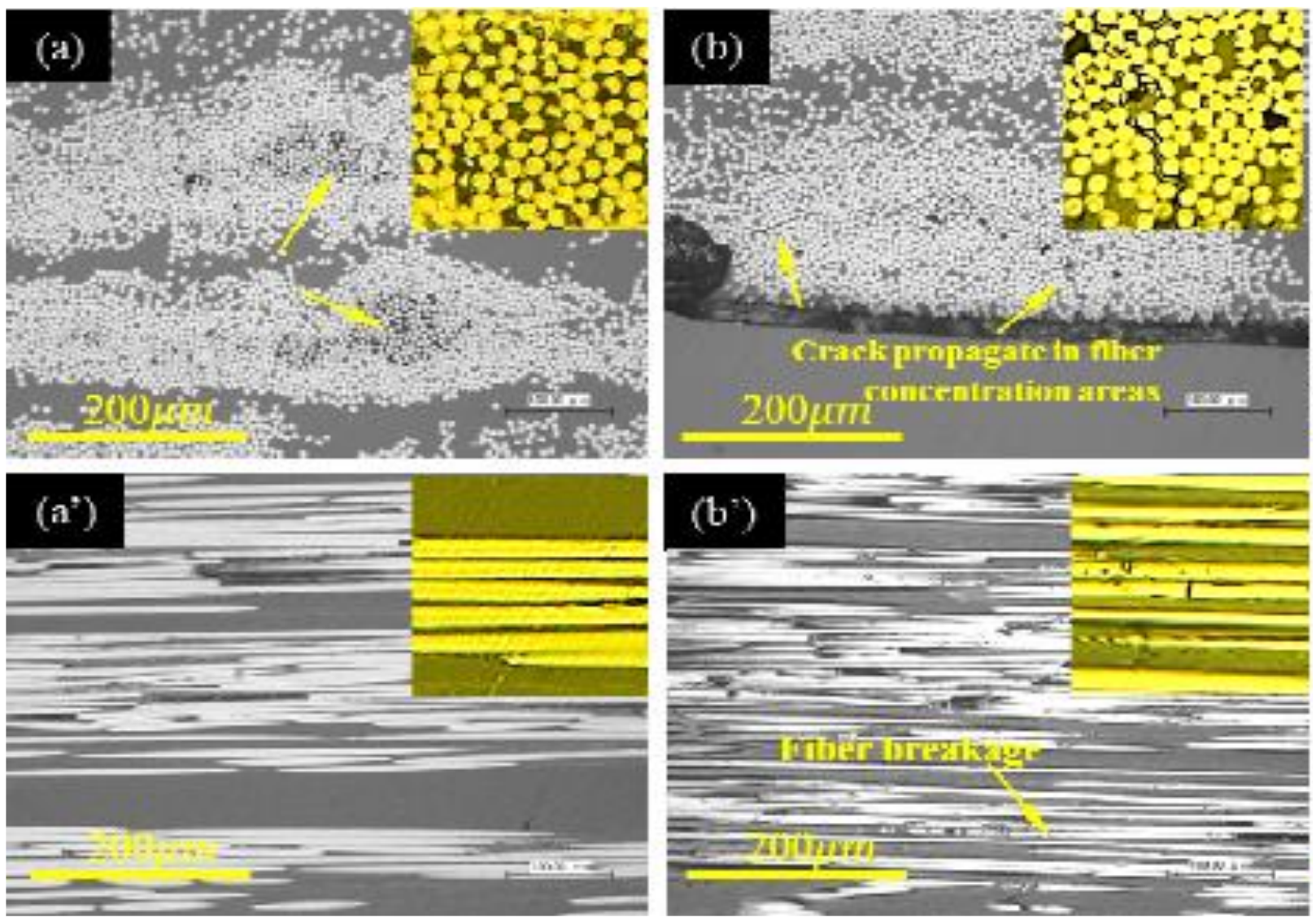

Fig. 7. Crack propagation in PA6/CF laminates under different axis tensile strain via cross-section and side-section observation. (a) and $\left(a^{\prime}\right)$ strain $0.2 \%$ : The first crack initiated from the fiber concentration bundles, in which insufficient bonding existed; (b) and (b') strain 0.8\%: Crack propagated in the concentration areas with little fiber breakage [50]

\section{Polyamide 6,6/carbon fiber}

Carbon fibers have been impregnated with polyamide 6,6 (PA6,6) resin using various manufacturing methods such as melt compounding, solution blending, matrix impregnation, etc. The progressive matrix/fiber interface possesses fine mechanical properties for aerospace applications [51].

Botelho et. al. [52] prepared polyamide 6,6 through interfacial polycondensation of hexamethylene diamine and adipoyl chloride. The obtained resin was impregnated on carbon fiber. The modification of carbon fiber affected the structural, chemical, and morphological characteristics of the composites. The PA6,6/CF composites with aligned $\mathrm{CF}$ had higher mechanical properties, compared with the neat PA6,6.

Botelho et. al. [53] formed PA6,6 and CF-based composites using reaction injection pultrusion (RIP) process. The PA6,6 was prepared by the interfacial polycondensation. The CF was suggested to develop interactions with the polyamide matrix. The SEM analysis validated the formation of polyamide-CF interface.

Karsli et. al. [54] also reinforced polyamide 6,6 with carbon fiber composite. The effect of carbon fiber sizing on the mechanical and thermomechanical properties of PA6,6/CF composites have been scrutinized. The tensile strength of sized CF-based composite was found higher than 
unsized CF filled composites. The thermal stability of sized CF-based composite was also greater than the unsized CF-based composites. SEM was used to study the interfacial bonding between PA 6,6 and CF composite. The superior properties were attributed to the interaction between matrix/filler.

Beylergil, et. al. [55] prepared electrospun polyamide 6,6 and carbon fiber-based nanofibers. The electrospun PA6,6/CF nanofiber has heightened the compressive strength, flexural modulus, tensile strength, impact resistance, and toughness. Initially, PA6,6 nanofiber was prepared by electrospinning. Then, PA6,6 nanofiber was deposited on CF surface through vacuum infusion. The mechanical strength of the composite fiber was enhanced with $\mathrm{CF}$ incorporation. However, the glass transition temperature of the PA6,6/CF composite was not affected by carbon fiber addition.

\section{Polyamide 11/carbon fiber}

The physico-chemical properties, shear strength, and interfacial adhesion strength of polyamide 11 (PA11) and carbon fiber composites have been determined [56, 57]. Zierdt et. al. [58] developed bio-based polyamide 11 and carbon fiber composites. Carbon fiber was modified using alkaline curing. The chemical treatment of carbon fiber improved the storage modulus and elastic modulus of the composites. Thermal stability of the PA11/CF material was also found to increase from 290 to $330{ }^{\circ} \mathrm{C}$. Thus, the thermal profile of the PA11/CF composite was considerably enhanced with the CF modification.

Lao et. al. [59] formed thermally stable and flame retardant PA11/CF composite. The materials were prepared using melt blending method. Low concentration of nanoclay nanoparticles were included as flame retardants. To enhance the non-flammability, contents of intumescent flame retardant were gradually increased in the polyamide 11/CF composites.

Zhang et. al. [60] produced polyamide-11 and polyaniline (PANI) blend-based composite fiber using wet-spinning technology. The SEM and transmission electron microscope (TEM) depicted two-phase fibriller morphology of the composites. Addition of polyaniline and carbon fiber upgraded the electrical conductivity of PA11/PANI/CF composite from $10^{-6}$ to $10^{-1} \mathrm{~S} / \mathrm{cm}$. The percolation threshold was found at $5 \mathrm{wt} . \%$ filler. Accordingly, polyamide11/CF composites have found potential for electrically strengthened engineered structure for advance applications.

\section{Polyamide 12/carbon fiber}

Carbon fiber in polyamide 12 (PA12) has led to high specific strength, relative to glass and other fiber fillers [61]. In this regard, oxidized and sized carbon fiber have been used for matrix compatiblization. The thin layer of PA12 on carbon fiber has significantly improved the fatigue resistance of PA12/CF. Interaction/adhesion between PA12 and CF may improve the gear, strength, and thermal stability of composite [62].

Wiedmer et. al. [63] developed PA12 yarn having discontinuous carbon fiber. The threepoint bending and shear tests were performed to study the mechanical properties. The pultrusion parameters (pulling speed, preheating) were studied. The pultruded profiles showed fine mechanical performance with void content $<2 \%$. The pulling speed was found to influence the quality of finally attained composite fiber. The variations in process parameters greatly affected the shear strength of the composites. Thus, fine mechanical strength, shear strength, and low void content were achieved. 
Erden et. al. [64] functionalized carbon fiber using continuous atmospheric plasma oxidation (APO) method. The APO was found to influence the surface properties of fibers. The single fiber fragmentation test was performed to study the interfacial shear strength of PA12/CF composites. The interfacial shear strength of PA12/CF were improved from 40 to $83 \mathrm{MPa}$. Similarly, interfacial adhesion of the materials was found to progress using APO modified CF filler. In addition, the contact angle measurements established the hydrophilic nature of APO-treated carbon fiber.

Kurokawa et. al. [65] prepared polyamide 12 and carbon fiber-based composite. The gear and wear performance of these materials were increased with filler loading. Better interfacial adhesion was observed between polyamide and fiber. The load capability and noiseless properties of the PA12/CF composites were found to enhance, compared with the neat polymer. The materials also depicted higher absorption capability than the polyamide. Hence, the development of advanced continuous fiber PA12 composites need surface modified CF filler to attain high performance PA12/CF.

\section{Polyamide 1010/carbon fiber}

Polyamide 1010 is an important type of aliphatic polyamide. Tribological characteristics of polyamide 1010 (PA1010)/carbon fiber composites have been investigated [66,67]. Wang et. al. [68] designed PA1010/carbon fiber composites using injection molding technique. The composites were explored for the influence of carbon fiber content on the tribological and wear properties. The 20 vol.\% loaded PA1010 has shown high wear resistance. The wear mechanism was supposed to be the thermo-fatigue performance. The low CF loading led to worn composite surface through micro-cutting.

Nikiforov et. al. [69] studied physicomechanical behavior of polyamide 1010/CF materials. The carbon fiber modified with short cellulose fiber were used as reinforcement. Inclusion of chopped cellulose fiber additives improved the physicomechanical properties of the polyamide 1010/modified CF composites, relative to neat CF-based materials. Further improvement in the strength properties were observed when the combination of carbon fiber, short cellulose fiber, and glass fiber was used.

Ge et. al. [70] prepared carbon fiber reinforced polyamide 1010 composite with the enhanced friction, wear, and mechanical properties. In this attempt, oxidized carbon fibers were employed. The tensile strength of PA1010/oxidized CF was found $10 \%$ higher than the neat CF-based materials. The maximum tensile strength of $82 \mathrm{MPa}$ was observed with 20 vol.\% CF.

Nikiforov et. al. [71] filled PA1010 with short carbon fiber using twin screw extrusion. The impact strength and tensile strength properties of PA1010/CF were enhanced with the addition of fibers. The polyamide 1010 and carbon fiber composites have extensive applications in automotive industry. Nowadays, bio-based PA1010 have been attempted to replace environmentally hazardous petroleum-based plastics.

\section{Aromatic polyamide/carbon fiber}

Similar to aliphatic polyamides, aromatic ones have also been reinforced with carbon fiber. Modeling studies of aromatic polyamide or aramid and CF-based composite have been performed for interfacial strength and crack-bridging competence [72]. 
Feldman et. al. [73] studied crystallinity of aramid/CF composite by high spatial resolution $\mathrm{X}$-ray diffraction. The crystallographic studied revealed grids of oriented lamellae along with fiber axis. The surface treated $\mathrm{CF}$ showed bi-layered transcrystallinity. The bi-layered transcrystalline fibers have shown the lamellar axis perpendicular to the angle $\sim 12^{\circ}$.

Won et. al. [74] studied the strength of aramid/CF composite by drilling tests. The machining parameters for aramid/CF composite laminates were measured using instrumented machining center. There was a direct relationship between the drilling forces and cutting parameters. The machining relations were considered essential to understand the design of intelligent controllers for proficient drilling laminate drilling. During drilling, the critical threshold feed rate was desired to evade damage.

Ma et. al. [75] prepared aramid and carbon fiber composite. The materials have revealed high energy absorption. The quasi static compression tests were used to study the energy absorption ability of the materials. Consequently, the specific energy absorption of $100 \mathrm{~kJ} / \mathrm{kg}$ was observed. The material's cross section area was microscopically analyzed to explore the failure mechanism. The optimum processing parameters may lead to the design of low cost and efficient high energy absorption components for engineering applicators.

Kozlov et. al. [76] formed carbon fiber reinforced aromatic polyamide network. Two types of polyamide/CF networks were developed: random superconducting network and random network of resistors. The heat transport and electrical conductivity of polyamide/CF with random superconducting network were found to enhance owing to network stability.

Hence, the energy absorption, toughening, electrical transport, thermal conduction, and strengthening mechanisms of aramid and carbon fiber-based composite depend on interfacial interaction and distribution of filler in the polyamide matrix.

\section{APPLICATIONS AND CHALLENGES OF POLYAMIDE/CARBON FIBER COMPOSITE}

Polyamide offers efficient thermoplastic matrices for carbon fibers. The thermoplastic polyamide composites have been developed using short, long or continuous carbon fibers. The polyamide/CF composites can be easily transformed into sheets, fibers, and coatings. These composites have remarkable temperature resistance, mechanical performance, and chemical stability, compared with thermosetting composites [77, 78]. Both the aliphatic and aromatic polyamide/CF-based high performance materials possess outstanding thermal stability and mechanical resistance $[79,80]$. Carbon fiber modification is also an important step to enhance the adhesion, interaction, and compatibility between matrix-fiber. Here, solubility and processability of polyamides can be enhanced using chemical functionalization of polymer backbone. However, polyamide/CF composites possess various technological and scientific processing challenges. Usually, high resin viscosity renders it difficult to impregnate the $\mathrm{CF}$ reinforcement. The infiltration difficulty may lead to design imperfection and non-homogeneous composites for commercial uses. The poor matrix-filler blending may directly affect the most challenging characteristic of composites i.e. structural strength. Among very important aspects of polyamide/CF composites are high strength and flame resistance i.e. demanding for aerospace, automobile, bullet-proof armor, protective clothing, sport fabrics, textiles, and other industrial applications [81]. Carbon fiber reinforced polyamide composite structures are promising for aerospace industries. Though, the introduction of polyamide/CF composites in up-to-date structures may be challenging owing to limited impact damage resistance and long term 
multifunctional properties. Conveyance of electrical current produced by lightning strike in aircraft/aerospace relevance is also challenging. Efforts have been made to dominate the automotive body parts with polyamide/CF as construction material, instead of metal. The car frames, bumpers, seats, whole automobile interior, and engine compartments have been built using these engineering composites. Polyamide/CF technology need to be further developed to meet the challenges of highly strengthened bullet-proof armor and fire-proof fabric. CFRP are cost-effective and long-lasting materials employed in strengthening concrete, masonry, steel, and cast iron structures for civil applications. In sports equipment, CFRP has been widely used in hockey sticks, tennis/badminton racquets, arrow shafts, surfboards, rowing shells, and several other sports accessories. CFRP has also found applications in high-end products for electronics and medical industries. To increase the binding strength of polyamide and $\mathrm{CF}$ for high performance CFRP products, inclusion of additives is desirable. Various additives/fillers employed in polyamide/CF composites include, nanocarbons (carbon nanotube, graphene, carbon black, etc.) and inorganic nanoparticles (silica, titania, clay, metal oxides, etc.). Future efforts must focus the novel design innovations using modified $\mathrm{CF}$, employing polyamide blends, and using advanced processing techniques, to attain high performance polyamide/CF composites.

\section{SUMMARY}

In short, this article presents a state-of-the-art review on polyamide/carbon fiber composites. Essential prospects of polyamide/carbon fiber composites have been considered including fundamentals of polyamide, $\mathrm{CF}$, processing strategies, and composite properties. Various types of carbon fiber-reinforced composites with improved mechanical properties have been reported. Here, binding interactions between the polyamide and carbon fiber were responsible for the formation of strengthened composites. Sizing, machining processes, and treatment of carbon fibers have been found responsible for varying morphologies, high electrical conductivity, thermal conductivity, and low thermal expansion of polyamide/CF composites. Applications and future challenges in the field of polyamide/CF composites have also been presented. The carbon fiber reinforced polyamide composites have been widely applied in aerospace, automobile, sports, military and construction industries owing to lightweight, high mechanical properties, thermal resistance, and chemical stability.

\section{REFERENCE}

1. Drobny, J.G.: Handbook of thermoplastic elastomers. Elsevier (2014).

2. Kausar, A.: Polyamide 1010/polythioamide blend reinforced with graphene nanoplatelet for automotive part application. Advances in Materials Science 17 (2017) 24-36.

3. Katunin, A., Krukiewicz, K., Herega, A. and Catalanotti, G.: 2016. Concept of a conducting composite material for lightning strike protection. Advances in Materials Science 16 (2016) 32-46.

4. Musztyfaga-Staszuk, M., Czupryński, A. and Kciuk, M.: Investigation of mechanical and anticorrosion properties of flame sprayed coatings. Advances in Materials Science 18 (2018) 42-53. 
5. Murthy, N.S.: Hydrogen bonding, mobility, and structural transitions in aliphatic polyamides. Journal of Polymer Science Part B: Polymer Physics 44(2006) 1763-1782.

6. Majumdar, B., Keskkula, H. and Paul, D.R.: Morphology development in toughened aliphatic polyamides. Polymer 35(1994) 1386-1398.

7. Yang, C.Q., Wang, X.L., Jiao, Y.J., Ding, Y.L., Zhang, Y.F. and Wu, Z.S.: Linear strain sensing performance of continuous high strength carbon fibre reinforced polymer composites. Composites Part B: Engineering 102 (2016) 86-93.

8. Yin, J., Liu, R.G., Huang, J.J., Liang, G., Liu, D. and Xie, G.H.: Comparative study on piezoresistive properties of CFRP tendons prepared by two different methods. Composites Part B: Engineering 129 (2017) 124-132.

9. Tibbetts, G.G. and McHugh, J.J.: Mechanical properties of vapor-grown carbon fiber composites with thermoplastic matrices. Journal of Materials Research 14 (1999) 2871-2880.

10. Ozkan, C., Karsli, N.G., Aytac, A. and Deniz, V.: Short carbon fiber reinforced polycarbonate composites: Effects of different sizing materials. Composites Part B: Engineering, 62 (2014) 230235.

11. Naskar, A.K., Keum, J.K. and Boeman, R.G.: Polymer matrix nanocomposites for automotive structural components. Nature nanotechnology, 11 (2016) 1026.

12. Kovács, T.A., Nyikes, Z. and Figuli, L.: Development of a Composite Material for Impact Load. Acta Materialia Transylvanica, 2 (2019) 105-109.

13. Ma, Y., Yang, Y., Sugahara, T. and Hamada, H.: A study on the failure behavior and mechanical properties of unidirectional fiber reinforced thermosetting and thermoplastic composites. Composites Part B: Engineering, 99 (2016) 162-172.

14 . Kim, S., Lee, J., Roh, C., Eun, J. and Kang, C.: Evaluation of carbon fiber and p-aramid composite for industrial helmet using simple cross-ply for protecting human heads. Mechanics of Materials, 139 (2019) 103203.

15 . Cerretini, G. and Giacomin, G.: Structural Reinforcement of a Masonry Building. In Key Engineering Materials 817 (2019) 673-679.

16. Amran, Y.M., Alyousef, R., Rashid, R.S., Alabduljabbar, H. and Hung, C.C.: Properties and applications of FRP in strengthening RC structures: A review. In Structures 16 (2018) 208-238. Elsevier.

17. Szakács, J. and Mészáros, L.: Synergistic effects of carbon nanotubes on the mechanical properties of basalt and carbon fiber-reinforced polyamide 6 hybrid composites. Journal of Thermoplastic Composite Materials, 31(2018) 553-571.

18 . Chen, H., Lim, C.L.J. and Fong, L.C.: PolyOne Corp, Polyamide compounds containing pitch carbon fiber. U.S. Patent 9,243,178 (2016).

19. Kuciel, S., Kuźnia, P. and Jakubowska, P.: Properties of composites based on polyamide 10.10 reinforced with carbon fiber. Polimery, 61 (2016).

20 . Shi, Z.Y., Cui, P. and Li, X.: A review on research progress of machining technologies of carbon fiber-reinforced polymer and aramid fiber-reinforced polymer. Proceedings of the Institution of Mechanical Engineers, Part C: Journal of Mechanical Engineering Science, 233 (2019) 4508-4520.

21. Kutz, M.: ed. Applied plastics engineering handbook: processing and materials. William Andrew (2011). 
22. Page, I.B.: Polyamides as engineering thermoplastic materials. Smithers Rapra Publishing, vol. 11, (2000).

23. Amintowlieh, Y., Sardashti, A. and Simon, L.C.: Polyamide 6-wheat straw composites: Effects of additives on physical and mechanical properties of the composite. Polymer Composites 33 (2012) 976-984.

24. Saba, N., Tahir, P.M. and Jawaid, M.: A review on potentiality of nano filler/natural fiber filled polymer hybrid composites. Polymers 6 (2014) 2247-2273.

25. Kwon, Y.N. and Leckie, J.O.: Hypochlorite degradation of crosslinked polyamide membranes: II. Changes in hydrogen bonding behavior and performance. Journal of membrane science 282 (2006) 456-464.

26. Chung, H.Y., Hall, J.R., Gogins, M.A., Crofoot, D.G. and Weik, T.M.: Donaldson Co Inc, Polymer, polymer microfiber, polymer nanofiber and applications including filter structures. U.S. Patent 7,090,715 (2006).

27. Lau, W.J., Gray, S., Matsuura, T., Emadzadeh, D., Chen, J.P. and Ismail, A.F.: A review on polyamide thin film nanocomposite (TFN) membranes: history, applications, challenges and approaches. Water research 80 (2015) 306-324.

28 . Akkapeddi, M.K., Glans, J.H., Dege, G.J. and Chung, S.J.: Honeywell International Inc, Polyamide compositions comprising aliphatic polyamide and an aromatic polyamide oligomer having improved moisture resistance. U.S. Patent 5,541,267 (1996).

29 . Tanner, D.A.V.I.D., Fitzgerald, J., Riewald, P.G. and Knoff, W.F.: Aramid structure/property relationships and their role in applications development. Marcel Dekker, Inc., Handbook of Fiber Science and Technology 3 (1989) pp.35-82.

30 . Slugin, I.V., Sklyarova, G.B., Kashirin, A.I. and Tkacheva, L.V.: Rusar para-aramid fibres for composite materials for construction applications. Fibre Chemistry 38 (2006) 25-26.

31. Singh, A.P., Garg, P., Alam, F., Singh, K., Mathur, R.B., Tandon, R.P., Chandra, A. and Dhawan, S.K.; 2012. Phenolic resin-based composite sheets filled with mixtures of reduced graphene oxide, $\gamma$ $\mathrm{Fe} 2 \mathrm{O} 3$ and carbon fibers for excellent electromagnetic interference shielding in the $\mathrm{X}$ band. Carbon 50(2012) 3868-3875.

32 . Frank, E., Steudle, L.M., Ingildeev, D., Spoerl, J.M. and Buchmeiser, M.R.: Carbon fibers: precursor systems, processing, structure, and properties. Angewandte Chemie International Edition 53(2014), 5262-5298.

33 . Chand, S.: Review carbon fibers for composites. Journal of materials science, 35 (2000), 1303-1313.

34 . Behabtu, N., Young, C.C., Tsentalovich, D.E., Kleinerman, O., Wang, X., Ma, A.W., Bengio, E.A., ter Waarbeek, R.F., de Jong, J.J., Hoogerwerf, R.E. and Fairchild, S.B.: Strong, light, multifunctional fibers of carbon nanotubes with ultrahigh conductivity. Science, 339 (2013), 182-186.

35 . Nataraj, S.K., Yang, K.S. and Aminabhavi, T.M.: Polyacrylonitrile-based nanofibers-A state-of-theart review. Progress in polymer science 37(2012) 487-513.

36. Dhand V, Mittal G, Rhee KY, Park S-J, Hui D.: A short review on basalt fiber reinforced polymer composites. Composites Part B: Engineering 73 (2015) 166-180.

37 . Liu, W., Mohanty, A.K., Askeland, P., Drzal, L.T., Misra, M.: Influence of fiber surface treatment on properties of Indian grass fiber reinforced soy protein based biocomposites. Polymer 45 (2004) 75897596. 
38. Xu, J., Ma, Y., Zhang, Q., Sugahara, T., Yang, Y., Hamada, H.: Crashworthiness of carbon fiber hybrid composite tubes molded by filament winding. Composite Structures. 139 (2016) 130-140.

39. Awad, Z.K., Aravinthan, T., Zhuge, Y., Gonzalez, F.: A review of optimization techniques used in the design of fibre composite structures for civil engineering applications. Materials \& Design. 33 (2012) 534-544.

40. Sharma M, Gao S, Mäder E, Sharma H, Wei LY, Bijwe J. Carbon fiber surfaces and composite interphases. Composites Science and Technology, 102 (2014) 35-50.

41 . Yao, S.S., Jin, F.L., Rhee, K.Y., Hui, D. and Park, S.J.: Recent advances in carbon-fiber-reinforced thermoplastic composites: A review. Composites Part B: Engineering 142 (2018) 241-250.

42 . An, H. J., Kim, J. S., Kim, K.-Y., Lim, D. Y. and Kim, D. H.: Mechanical and thermal properties of long carbon fiber-reinforced polyamide 6 composites. Fibers and Polymers 15 (2014) 2355-2359.

43 . Li, J. and Zhang, Y.F.: The tensile properties of short carbon fiber reinforced ABS and ABS/PA6 composites. Journal of Reinforced Plastics and Composites, 29 (2020) 1727-1733.

44 . Luo, H., Xiong, G., Ma, C., Li, D. and Wan, Y.: Preparation and performance of long carbon fiber reinforced polyamide 6 composites injection-molded from core/shell structured pellets. Materials \& Design, 64 (2014) 294-300.

45 . Yi, J.W., Lee, W., Seong, D.G., Won, H.J., Kim, S.W., Um, M.K. and Byun, J.H.: Effect of phenoxybased coating resin for reinforcing pitch carbon fibers on the interlaminar shear strength of PA6 composites. Composites Part A: Applied Science and Manufacturing, 87 (2016) 212-219.

46. Wu, S.H., Wang, F.Y., Ma, C.C.M., Chang, W.C., Kuo, C.T., Kuan, H.C. and Chen, W.J.: 2001. Mechanical, thermal and morphological properties of glass fiber and carbon fiber reinforced polyamide-6 and polyamide-6/clay nanocomposites. Materials Letters, 49 (2001) 327-333.

47 . Li, J.: Interfacial studies on the $\mathrm{O}_{3}$ modified carbon fiber-reinforced polyamide 6 composites. Applied Surface Science, 255 (2008) 2822-2824.

48 . Karsli, N.G. and Aytac, A.: Tensile and thermomechanical properties of short carbon fiber reinforced polyamide 6 composites. Composites Part B: Engineering, 51 (2013) 270-275.

49. Li J, Zhang YF.: The tensile properties of $\mathrm{HNO}_{3}$-treated carbon fiber reinforced ABS/PA6 composites. Surface and Interface Analysis 41(2009) 610-614.

50 . Ma, Y., Ueda, M., Yokozeki, T., Sugahara, T., Yang, Y. and Hamada, H.: A comparative study of the mechanical properties and failure behavior of carbon fiber/epoxy and carbon fiber/polyamide 6 unidirectional composites. Composite Structures, 160 (2017) 89-99.

51 . Costa, A.P.D., Botelho, E.C., Costa, M.L., Narita, N.E. and Tarpani, J.R.: A review of welding technologies for thermoplastic composites in aerospace applications. Journal of Aerospace Technology and Management, 4 (2012) 255-265.

52 . Botelho, E.C., Scherbakoff, N. and Rezende, M.C.: Study of polyamide 6/6 synthesis carried out by interfacial polymerization on carbon fibre. Polymer international, 51 (2002) 1261-1267.

53 . Botelho, E.C., Scherbakoff, N., Rezende, M.C., Kawamoto, A.M. and Sciamareli, J.: Synthesis of polyamide $6 / 6$ by interfacial polycondensation with the simultaneous impregnation of carbon fibers. Macromolecules, 34 (2001) 3367-3375.

54 . Karsli, N.G., Ozkan, C., Aytac, A. and Deniz, V.: Effects of sizing materials on the properties of carbon fiber-reinforced polyamide 6, 6 composites. Polymer Composites, 34 (2013) 1583-1590. 
55. Beylergil, B., Tanoğlu, M. and Aktaş, E.: Enhancement of interlaminar fracture toughness of carbon fiber-epoxy composites using polyamide-6, 6 electrospun nanofibers. Journal of Applied Polymer Science, 134 (2017) 45244.

56. Jin, X., Sun, J., Zhang, J.S., Gu, X., Bourbigot, S., Li, H., Tang, W. and Zhang, S.: Preparation of a novel intumescent flame retardant based on supramolecular interactions and its application in polyamide 11. ACS applied materials \& interfaces, 9 (2017) 24964-24975.

57 . Bai, J., Yuan, S., Shen, F., Zhang, B., Chua, C.K., Zhou, K. and Wei, J.: Toughening of polyamide 11 with carbon nanotubes for additive manufacturing. Virtual and Physical Prototyping, 12 (2017) 235240 .

58 . Zierdt, P., Theumer, T., Kulkarni, G., Däumlich, V., Klehm, J., Hirsch, U. and Weber, A.: Sustainable wood-plastic composites from bio-based polyamide 11 and chemically modified beech fibers. Sustainable Materials and Technologies, 6 (2015) 6-14.

59 . Lao, S.C., Yong, W., Nguyen, K., Moon, T.J., Koo, J.H., Pilato, L. and Wissler, G.: Flame-retardant polyamide 11 and 12 nanocomposites: processing, morphology, and mechanical properties. Journal of composite materials, 44 (2010) 2933-2951.

60 . Zhang, Q., Jin, H., Wang, X. and Jing, X.: Morphology of conductive blend fibers of polyaniline and polyamide-11. Synthetic Metals, 123 (2001) 481-485.

61. Sandler, J.K.W., Pegel, S., Cadek, M., Gojny, F., Van Es, M., Lohmar, J., Blau, W.J., Schulte, K., Windle, A.H. and Shaffer, M.S.P.: A comparative study of melt spun polyamide-12 fibres reinforced with carbon nanotubes and nanofibres. Polymer, 45 (2004) 2001-2015.

62 . Perrot, C., Piccione, P.M., Zakri, C., Gaillard, P. and Poulin, P.: Influence of the spinning conditions on the structure and properties of polyamide 12/carbon nanotube composite fibers. Journal of Applied Polymer Science, 114 (2009) 3515-3523.

63. Wiedmer, S. and Manolesos, M.: An experimental study of the pultrusion of carbon fiber-polyamide 12 yarn. Journal of thermoplastic composite materials, 19 (2006) 97-112.

64 . Erden, S., Ho, K.K., Lamoriniere, S., Lee, A.F., Yildiz, H. and Bismarck, A.: Continuous atmospheric plasma oxidation of carbon fibres: influence on the fibre surface and bulk properties and adhesion to polyamide 12. Plasma Chemistry and Plasma Processing, 30 (2010) 471-487.

65 . Kurokawa, M., Uchiyama, Y., Iwai, T. and Nagai, S.: Performance of plastic gear made of carbon fiber reinforced polyamide 12. Wear, 254 (2003) 468-473.

66. Wang, J., Gu, M., Zhu, Z., Ge, S. and Liu, W.: Tribological properties of hybrid carbon fiber and MoS 2 reinforced polyamide 1010 composites. Fuhe Cailiao Xuebao (Acta Materiae Compositae Sinica, China), 20 (2003) 13-18.

67 . Wang, J.X., Ge, S.R. and Li, L.: Effect of counterpart surface roughness on the tribological behavior of carbon fiber reinforced polyamide 1010 composites. Mocaxue Xuebao (Tribology, China), 21 (2001) 106-109.

68. WANG, J.X. and GU, M.Y.: Tribological Behaviors and Wear Mechanism of Carbon Fiber Reinforced Nylon 1010 Composites. Materials For Mechanical Engineering, 7 (2003).

69. Nikiforov, A.A., Vol'fson, S.I., Okhotina, N.A., Rinberg, R., Hartmann, T. and Kroll, L.: Mechanical properties of the compositions based on biopolyamide-1010 modified by carbon, glass, and cellulose chopped fibers. Russian Metallurgy (Metally), 4 (2017) 279-282. 
70 . Ge, S., Zhang, D., Zhu, H. and Wang, J.: Mechanical properties and their influence on the friction and wear of the carbon fibers reinforced polyamide 1010. Fuhe Cailiao Xuebao(Acta Mater. Compos. Sin., China), 21(2004) 99-104.

71. Nikiforov, A.A., Okhotina, N.A., Fayzullin, I.Z., Volfson, S.I., Rinberg, R. and Kroll, L., 2016, November. Stress-strain properties of composites based on bio-based polyamide 1010 filled with cut fibers. In AIP Conference Proceedings, AIP Publishing, vol. 1785 (2016) 030018.

72. Sun, Z., Hu, X., Sun, S. and Chen, H.: Energy-absorption enhancement in carbon-fiber aluminumfoam sandwich structures from short aramid-fiber interfacial reinforcement. Composites Science and Technology, 77 (2013) 14-21.

73. Feldman, A.Y., Gonzalez, M.F., Wachtel, E., Moret, M.P. and Marom, G.: Transcrystallinity in aramid and carbon fiber reinforced nylon 66: determining the lamellar orientation by synchrotron Xray micro diffraction. Polymer, 45 (2004) 7239-7245.

74 . Won, M.S. and Dharan, C.K.H.: Drilling of aramid and carbon fiber polymer composites. Journal of Manufacturing Science and Engineering, 124 (2002) 778-783.

75. Ma, Y., Sugahara, T., Yang, Y. and Hamada, H.: A study on the energy absorption properties of carbon/aramid fiber filament winding composite tube. Composite Structures, 123 (2015) 301-311.

76. Kozlov, G.V., Burya, A.I., Dolbin, I.V. and Zaikov, G.E.: Fractal model of the heat conductivity for carbon fiber-reinforced aromatic polyamide. Journal of applied polymer science, 100 (2006) 38283831.

77 . Duchoslav, J., Unterweger, C., Steinberger, R., Fürst, C. and Stifter, D.: Investigation on the thermooxidative stability of carbon fiber sizings for application in thermoplastic composites. Polymer Degradation and Stability, 125 (2016) 33-42.

78 . Hofstätter, T., Pedersen, D.B., Tosello, G. and Hansen, H.N.: State-of-the-art of fiber-reinforced polymers in additive manufacturing technologies. Journal of Reinforced Plastics and Composites, 36 (2017) 1061-1073.

79 . Trigo-López, M., Barrio-Manso, J.L., Serna, F., García, F.C. and García, J.M.: Crosslinked Aromatic Polyamides: A Further Step in High-Performance Materials. Macromolecular Chemistry and Physics, 214 (2013) 2223-2231.

80 . Trigo-López, M., Estévez, P., San-José, N., Gómez-Valdemoro, A., García, F.C., Serna, F., Pena, J.L. and García, J.M.: Recent patents on aromatic polyamides. Recent Patents on Materials Science, 2 (2009) 190-208.

81. Dike, A.S.: Improvement of mechanical and physical properties of carbon fiber-reinforced polyamide composites by applying different surface coatings for short carbon fiber. Journal of Thermoplastic Composite Materials, (2009) 0892705719877218. 